\title{
Predictive value of maternal second-generation thyroid-binding inhibitory immunoglobulin assay for neonatal autoimmune hyperthyroidism
}

\author{
Juliette Abeillon-du Payrat 1,2,10,+, Karim Chikh 1,8,11, Nadine Bossard ${ }^{1,15}$, \\ Patricia Bretones ${ }^{1,3}$, Pascal Gaucherand 1,5,10, Olivier Claris 1,6,10, Anne Charrié ${ }^{1,8,13}$, \\ Véronique Raverot $^{1,7}$, Jacques Orgiazzi 1,9,12, Françoise Borson-Chazot ${ }^{1,2,10,14}$ and \\ Claire Bournaud ${ }^{1,4,10,14}$ \\ ${ }^{1}$ Hospices Civils de Lyon, Lyon, France, ${ }^{2}$ Fédération d'Endocrinologie, ${ }^{3}$ Service d'Endocrinologie Pédiatrique, \\ ${ }^{4}$ Service de Médecine Nucléaire, ${ }^{5}$ Service de Gynécologie-Obstétrique, ${ }^{6}$ Service de Néonatalogie and \\ ${ }^{7}$ Service de Biochimie, Groupement Hospitalier Est, F-69003 Lyon, France, ${ }^{8}$ Service de Biochimie and \\ ${ }^{9}$ Service d'Endocrinologie, Centre Hospitalier Lyon Sud, 69310 Lyon, France, ${ }^{10}$ Faculté de Médecine Lyon-Est, \\ Université Lyon 1, Lyon, France, ${ }^{11}$ Faculté de Pharmacie, Lyon, France, ${ }^{12}$ Faculté de Médecine et de Maïeutique Lyon \\ Sud - Charles Mérieux, Lyon, France, ${ }^{13}$ CARMEN INSERM U1060, Lyon, France, ${ }^{14}$ INSERM U1052, Lyon, France and \\ ${ }^{15}$ Service de Biostatistiques, 162 Avenue Lacassagne, 69003 Lyon, France \\ †J Abeillon-du Payrat is now at Fédération d'Endocrinologie, Groupement Hospitalier Est, 59 Bd Pinel, \\ 69677 Bron Cedex, France
}

Correspondence should be addressed to J Abeillon-du Payrat Email

juliette.abeillon@chu-lyon.fr

\begin{abstract}
Context: Hyperthyroidism occurs in $1 \%$ of neonates born to mothers with active or past Graves' disease (GD). Current guidelines for the management of GD during pregnancy were based on studies conducted with first-generation thyroid-binding inhibitory immunoglobulin (TBII) assays.

Objective: This retrospective study was conducted in order to specify the second-generation TBII threshold predictive of fetal and neonatal hyperthyroidism, and to identify other factors that may be helpful in predicting neonatal hyperthyroidism. Methods: We included 47 neonates born in the Lyon area to 42 mothers harboring measurable levels of TBII during pregnancy. TBII measurements were carried out in all mothers; bioassays were carried out in 20 cases.

Results: Nine neonates were born with hyperthyroidism, including five with severe hyperthyroidism requiring treatment. Three neonates were born with hypothyroidism. All hyperthyroid neonates were born to mothers with TBII levels $>5$ IU/l in the second trimester (sensitivity, $100 \%$ and specificity, 43\%). No mother with TSH receptor-stimulating antibodies (TSAb measured by bioassay) below $400 \%$ gave birth to a hyperthyroid neonate. Among mothers of hyperthyroid neonates, who required antithyroid drugs during pregnancy, none could stop treatment before delivery. Analysis of TBII evolution showed six unexpected cases of increasing TBII values during pregnancy.

Conclusion: Maternal TBII value over $5 \mathrm{IU} / \mathrm{l}$ indicates a risk of neonatal hyperthyroidism. Among these mothers, a TSAb measurement contributes to identify more specifically those who require a close fetal thyroid ultrasound follow-up. These results should be confirmed in a larger series.
\end{abstract}

(c) 2014 European Society of Endocrinology Printed in Great Britain
European Journal of Endocrinology (2014) 171, 451-460 


\section{Introduction}

One percent of pregnant women have been previously treated or are being treated for Graves' hyperthyroidism $(1,2)$. Among them, $1 \%$ will give birth to a hyperthyroid neonate $(3,4,5)$. During normal fetal development, the thyroid gland begins to synthesize thyroid hormones from 10 to 12 weeks of gestation, and the thyroid-stimulating hormone receptor (TSHR) responsiveness to TSH develops at about 20 weeks of pregnancy $(6,7,8,9)$. Therefore, maternal TSH receptor antibodies (TRAb) that are transferred to the fetus through the placenta may stimulate the fetal thyroid gland and cause goiter and hyperthyroidism in the fetus during the second half of pregnancy $(10,11)$. Antithyroid drugs (ATDs) also cross the placenta, exposing the fetus to a risk of hypothyroidism. Thus, pregnancy in Graves' disease (GD) patients represents a challenging situation.

There are two currently available methods for measuring TRAb: 'receptor assays' measuring thyroid-binding inhibitory immunoglobulins (TBII) and 'bioassays' measuring the ability of TRAb to stimulate (TSHR-stimulating antibodies (TSAb)) or inhibit (TSHR-blocking antibodies (TBAb)) TSHR-mediated production of cAMP.

Recent guidelines for the management of GD $(12,13)$ during pregnancy has identified at-risk situations for fetal and neonatal thyroid dysfunction, including high maternal levels of TRAb during the second trimester. Accordingly, expectant mothers with TRAb values of two to three times the upper limit of normal should be monitored closely. Most related studies have been performed using the first-generation TBII assay and yet second-generation assays are nowadays widely available. Instead of solubilized porcine receptors $(14,15)$, these newer assays use recombinant TSHR coated on a solid-phase surface which provides a markedly improved sensitivity and specificity $(16,17,18)$. To our knowledge, the threshold value indicating a risk for fetal or neonatal autoimmune hyperthyroidism with a second-generation TBII assay has only been investigated in one small study (19).

We performed a retrospective study on women living in and around Lyon in France, who presented an active or a previous history of GD and positive TBII during their pregnancy. Our aim was to define the TBII concentration threshold, using a second-generation assay, indicating a risk for fetal hyperthyroidism.

\section{Subjects and methods}

Patients living in and around Lyon, France, were identified through different methods: surveys among specialist consultants and screening of databases from Endocrinology and Obstetrics Departments, and TRAb bioassays were carried out in Lyon University Hospital.

Inclusion criteria were active or past history of GD, at least one positive TRAb value during pregnancy, and complete clinical data regarding both the mother and her neonate. We identified 127 neonates born between 2001 and 2012. Among them, 53 TRAb-negative women and 27 incomplete files were excluded. Finally, 47 neonates born to 42 mothers (twin pregnancies, $n=2$ and successive pregnancies, $n=3$ ) were included in this study.

The thyroid status of mothers was determined based on serum TSH levels in the mothers cured of GD before pregnancy, and on serum TSH and free thyroxine ( $\mathrm{fT}_{4}$ ) levels adapted to the trimester of pregnancy as reported previously (20) in case of active GD. In the neonates, it was defined based on serum TSH and $\mathrm{fT}_{4}$ sampled in the first week in 38, and on TSH only, determined on capillary sampling performed for the neonatal screening for congenital hypothyroidism, in nine euthyroid neonates $(21,22)$.

TBII analysis was carried out in 33 women during the first trimester (T1), in 32 during the second (T2), and in 34 during the third (T3) (Table 1). The neonatal thyroid status was then considered with regards to the TBII values measured preferably during $\mathrm{T} 2$ or, if not available, those at T3. TBII evolution was studied in 42 mothers for whom at least two TBII determinations had been performed either during pregnancy, or immediately before and during pregnancy. Variation of more than $20 \%$ of the initial value was considered as clinically meaningful.

TRAb bioassays were performed for 20 women either at the time of pregnancy or using frozen serum at the time of the study. Bioassays were performed in 16 women during the second half of pregnancy. For the remaining four patients, a bioassay performed during T1 was considered to be representative for the rest of pregnancy on the basis of clinical and biological evolution.

\section{TRAb assays}

TBII assay $\downarrow$ TBII value was quantified in all patients using a commercially available radioreceptor assay kit (TRAK human, Thermo Fischer Scientific, Clinical Diagnostics, B.R.A.H.M.S GmbH, Hennigsdorf, Germany). Briefly, the detection of TBII concentration was based on the ability of autoantibodies to bind to the TSHR, thus inhibiting the binding of radiolabeled bovine TSH (bTSH). The kit used tubes that are coated with human recombinant TSHR and 
Table 1 Clinical characteristics of the mothers during TBII analysis. Median (range) TBII (IU/I), and evolution of TBII in patients with at least two determinations during pregnancy. Median values were used because of the scattering of TBII values in this population.

\begin{tabular}{|c|c|c|c|c|c|c|c|}
\hline & \multirow[b]{2}{*}{$n$} & \multicolumn{3}{|c|}{ Median (range) TBII } & \multicolumn{3}{|c|}{$\begin{array}{c}\text { Evolution of TBII } \\
\text { during pregnancy }(n=42)\end{array}$} \\
\hline & & $\mathrm{T} 1, n=33$ & $\mathrm{~T} 2, n=32$ & $\mathrm{~T} 3, n=34$ & Increase & Decrease & Stable \\
\hline Active GD & 25 & $10.4(2.6-214)$ & $5.6(1-102)$ & $5.3(0.4-258)$ & $n=2$ & $n=19$ & $n=2$ \\
\hline $\begin{array}{l}\text { Treatment initiated before } \\
\text { pregnancy }\end{array}$ & 12 & $114.15(3-214)$ & $8.2(1.2-102)$ & $6.3(<0.4-94.5)$ & $n=1$ & $n=10$ & \\
\hline Diagnosis during pregnancy & 10 & $13.25(4.1-28)$ & $3.6(1-42.5)$ & $3.1(0.6-258)$ & $n=1$ & $n=9$ & \\
\hline Relapse during pregnancy & 3 & $3.05(2.6-3.5)$ & 2.1 & $4.55(3.5-5.6)$ & & & $n=2$ \\
\hline Past history of GD & 20 & $8.2(2.1-409)$ & $14.8(2.1-96.5)$ & $12.5(1.5-251)$ & $n=4$ & $n=10$ & $n=5$ \\
\hline $\begin{array}{l}\text { Supplemented hypothyroidism } \\
\text { following radical treatment } \\
\text { (RAI } n=7 \text {, surgery } n=7 \text { ) }\end{array}$ & 14 & $20(2.2-49)$ & $13.9(2.1-96.5)$ & $12.5(1.5-251)$ & $n=2$ & $n=9$ & $n=3$ \\
\hline $\begin{array}{l}\text { Euthyroidism following ATD } \\
\text { treatment }\end{array}$ & 3 & $3.75(2.5-5)$ & 2.2 & 7.3 & $n=1$ & & $n=1$ \\
\hline $\begin{array}{l}\text { Supplemented hypothyroidism } \\
\text { following ATD treatment }\end{array}$ & 3 & $21.6(2.1-41.1)$ & $40.25(20-60.5)$ & $83(31.1-135)$ & $n=1$ & $n=1$ & $n=1$ \\
\hline All the cohort & 45 & $10.3(2.1-214)$ & $8.7(1-102)$ & $5.9(0.4-258)$ & $14 \%$ & $69 \%$ & $17 \%$ \\
\hline
\end{tabular}

human standard material. One international unit (IU) of this TRAK human RIA is equivalent to $1 \mathrm{IU}$ of TSAb (WHO standard 90/672). The assay result was considered as positive above a cutoff value of $1.5 \mathrm{IU} / 1$.

TSAb and TBAb bioassays - TSAb and TBAb bioassays were carried out in the Biology Department of the Hospices Civils de Lyon Sud University Hospital.

The CHO cells (strain JP-26), transfected with the recombinant human TSHR, were used to detect TSAb and TBAb, as shown previously (23). The CHO JP-26 cells were seeded into 96-well plates (50 000 cells/well), cultured in Ham's F12 medium, containing 5\% calf serum, and used for TSAb and TBAb bioassays $24 \mathrm{~h}$ after seeding.

The CHO cells were exposed for $2 \mathrm{~h}$ to $4 \mu \mathrm{l}$ of test serum or control serum in $196 \mu$ l of modified Kasagi et al.'s (24) hypotonic medium supplemented with $10 \mathrm{mM}$ HEPES, $0.25 \mathrm{mmol} / \mathrm{l}$ isobutylmethylxanthine, and $0.75 \%$ $\mathrm{BSA}, \mathrm{pH}$ 7.4. For the TBAb bioassay, the hypotonic medium was supplemented with bTSH $(0.1 \mathrm{mIU} / \mathrm{ml})$. After incubation, cAMP released from the cells was measured with a commercial RIA Kit (RIA cAMP, IMMUNOTECH, a Beckman Coulter Company, Marseille, France) according to the manufacturer's instructions. Pooled TRAb-negative sera (normal sera) were used to measure cAMP basal production, pooled TSAb-positive sera were used as positive controls in TSAb assay and pooled TBAbpositive sera as positive controls in TBAb assay.

$\mathrm{TSAb}$ activity was expressed as a percentage of cAMP basal production: TSAb activities ranging from 140 to $200 \%$ were considered as weak, $200-400 \%$ as moderate, and $\geq 400 \%$ as strong. TBAb activities were calculated and expressed as follows: $(1-(a / b)) \times 100$, where $(a)$ is the cAMP generated in the presence of the patient's sample and bTSH and $(b)$ is the cAMP generated in the presence of normal sera and bTSH. Weak TBAb activities were those ranging from 10 to $20 \%$, moderate from 20 to $40 \%$, and strong higher than $40 \%$. The assays were run in triplicate and results are expressed as the mean of the three data. Variability between assays is $8.6 \%$ for TSAb and $7.1 \%$ for TBAb.

\section{Statistical analysis}

For the comparison between two groups we used either nonparametric Mann-Whitney's $U$ test for numerical variable or Pearson's $\chi^{2}$ for nominative variable. A probability of $<0.05$ was considered significant. Statistical analysis included ROC curve design, and determination of sensitivity and specificity derived from the receiver operating characteristic (ROC) curves.

\section{Ethics committee}

The study was approved by the Hospices Civils de Lyon Local Ethics Committee.

\section{Results}

\section{Clinical characteristics of the mothers}

The characteristics of the mothers are summarized in Table 1, each pregnancy being considered as an independent event. Individual cases are shown in Table 2. The 
Table 2 Characteristics of the 47 neonates (neonates nos 33 and 34, and 36 and 37 are twins), thyroid status and TBII of their mothers. Among 47, nine neonates were born with hyperthyroidism, 35 with euthyroidism, and three with hypothyroidism.

\begin{tabular}{|c|c|c|c|}
\hline Case no. ${ }^{a}$ & Neonatal status & Maternal status & Maternal T2 TBII (IU/I) \\
\hline 1 & $\begin{array}{l}\text { Hyperthyroidism } \\
\text { (treatment) }\end{array}$ & Euthyroidism on $\mathrm{L}^{-\mathrm{T}_{4}}$ (RAI) & 14 \\
\hline 2 & $\begin{array}{l}\text { Hyperthyroidism } \\
\text { (treatment) }\end{array}$ & Euthyroidism on L-T 4 (surgery) & 96.5 (rise) \\
\hline 3 & $\begin{array}{l}\text { Hyperthyroidism } \\
\text { (treatment) }\end{array}$ & Active $G D^{b, c}$ & 17 \\
\hline 4 & $\begin{array}{l}\text { Hyperthyroidism } \\
\text { (treatment) }\end{array}$ & Active $G^{c}$ & 102 \\
\hline 5 & $\begin{array}{l}\text { Hyperthyroidism } \\
\text { (treatment) }\end{array}$ & Active GD (lost to FU) & 258 (T3) (rise) \\
\hline 6 & Hyperthyroidism & Active $\mathrm{GD}^{\mathrm{a}}$ (untreated) & $5.6($ (T3) \\
\hline 7 & Hyperthyroidism & Active $\mathrm{GD}^{c}$ & 30.8 \\
\hline 8 & Hyperthyroidism & Euthyroidism on $\mathrm{L}^{-\mathrm{T}_{4}}$ (surgery) & 11 \\
\hline 9 & Hyperthyroidism & Euthyroidism on $L-\mathrm{T}_{4}$ (surgery) & 26.9 \\
\hline 10 & Euthyroidism & Active $\mathrm{GD}^{\mathrm{C}}$ & 8.3 \\
\hline 11 & Euthyroidism & Active $\mathrm{GD}^{\mathrm{d}}$ & 2.2 \\
\hline 12 & Euthyroidism & Active $\mathrm{GD}^{\mathrm{d}}$ & 8.7 \\
\hline 13 & Euthyroidism & Euthyroidism on $\mathrm{L}^{-\mathrm{T}_{4}}$ (RAI) & 15 \\
\hline 14 & Euthyroidism & Euthyroidism on $\mathrm{L}^{-\mathrm{T}_{4}}$ (RAI) & 5.2 (T3) \\
\hline 15 & Euthyroidism & Active $\mathrm{GD}^{\mathrm{d}}$ & 3.6 \\
\hline 16 & Euthyroidism & Euthyroidism on L-T 4 (RAI) & 2.1 \\
\hline 17 & Euthyroidism & Euthyroidism (ATD) & 2.2 \\
\hline 18 & Euthyroidism & Active $\mathrm{GD}^{\mathrm{d}}$ & $2.8(\mathrm{~T} 3)$ \\
\hline 19 & Euthyroidism & Active GD & 7.5 \\
\hline 20 & Euthyroidism & Active $\mathrm{GD}^{\mathrm{d}}$ & 3.6 \\
\hline 21 & Euthyroidism & Active $\mathrm{GD}^{\mathrm{c}}$ & 12.7 \\
\hline 22 & Euthyroidism & Euthyroidism (ATD) & $5(\mathrm{~T} 1)$ \\
\hline 23 & Euthyroidism & Active GD ${ }^{c}$ & 8.2 \\
\hline 24 & Euthyroidism & Active $\mathrm{GD}^{\mathrm{d}}$ & 1.3 \\
\hline 25 & Euthyroidism & Euthyroidism on L-T ${ }_{4}$ (ATD) & $2.1(\mathrm{~T} 1)$ \\
\hline 26 & Euthyroidism & Euthyroidism on $\mathrm{L}^{-\mathrm{T}_{4}}$ (surgery) & $3.1(\mathrm{~T} 1)$ \\
\hline 27 & Euthyroidism & Active GD & 1.2 \\
\hline 28 & Euthyroidism & Active $\mathrm{GD}^{\mathrm{a}, \mathrm{d}}$ & 2.1 \\
\hline 29 & Euthyroidism & Euthyroidism on L-T 4 (ATD) & 20 \\
\hline 30 & Euthyroidism & Euthyroidism on $L-T_{4}$ (ATD) & 60 (rise) \\
\hline 31 & Euthyroidism & Euthyroidism on $\mathrm{L}^{-\mathrm{T}_{4}}$ (surgery) & 11 (rise) \\
\hline 32 & Euthyroidism & Euthyroidism on $\mathrm{L}^{-\mathrm{T}_{4}}$ (surgery) & 20.5 \\
\hline 33 (twin) & Euthyroidism & Active $G^{d}$ & 2.7 \\
\hline 34 (twin) & Euthyroidism & Active $G^{d}$ & 2.7 \\
\hline 35 & Euthyroidism & Active GD ${ }^{c}$ & $6.3($ (T3) \\
\hline 36 (twin) & Euthyroidism & Euthyroidism (ATD) & 7.3 (T3) (rise) \\
\hline 37 (twin) & Euthyroidism & Euthyroidism (ATD) & 7.3 (T3) (rise) \\
\hline 38 & Euthyroidism & Euthyroidism on $\mathrm{L}^{-\mathrm{T}_{4}}$ (RAI) & 8.7 \\
\hline 39 & Euthyroidism & Active $\mathrm{GD}^{\mathrm{b}}$ & 13.2 (rise) \\
\hline 40 & Euthyroidism & Active GD ${ }^{a}$ & 3.5 (Т3) \\
\hline 41 & Euthyroidism & Euthyroidism on L-T 4 (RAI) & 13 \\
\hline 42 & Euthyroidism & Euthyroidism on L-T 4 (surgery) & 6.5 (T3) \\
\hline 43 & Euthyroidism & Active $\mathrm{GD}^{\mathrm{d}}$ & 3.7 \\
\hline 44 & Euthyroidism & Active GD ${ }^{d}$ & 1 \\
\hline 45 & $\begin{array}{l}\text { Transient } \\
\text { hypothyroidism }\end{array}$ & Active $G^{c}$ & $<0.4(\mathrm{~T} 3)$ \\
\hline 46 & $\begin{array}{l}\text { Transient } \\
\text { hypothyroidism }\end{array}$ & Euthyroidism on $\mathrm{L}^{-\mathrm{T}_{4}}$ (RAI) & $2.2(\mathrm{~T} 1)$ \\
\hline 47 & $\begin{array}{l}\text { Transient } \\
\text { hypothyroidism }\end{array}$ & Active $\mathrm{GD}^{\mathrm{d}}$ & 42.5 \\
\hline
\end{tabular}

$\begin{array}{ll}\frac{\text { Bioassay (TSAb/TBAb) }}{\text { No }} & \frac{\text { Neonatal TBII (IU/l) }}{7} \\ \text { No } & 348\end{array}$

No 13.1

$973 \% /<10 \% \quad 48.2$

$1584 \% /<10 \%$

No

No $\quad 11.4$

$412 \% /<10 \% \quad 6.5$

$863 \% /<10 \% \quad$ NA

$102 \% /<10 \% \quad$ NA

No NA

No NA

$111 \% / 22.8 \% \quad 11.2$

No NA

No $\quad 4.2$

No 1

No NA

No $\quad 1.4$

No NA

$391 \% /<10 \% \quad$ NA

No $\quad 1.3$

No $\quad 5.7$

No $\quad 1.4$

$126 \% /<10 \% \quad 0.9$

No NA

$108 \% /<10 \% \quad 2.2$

$162 \% / 10 \% \quad$ Neg

No NA

$48 \% / 88 \% \quad$ NA

$73 \% / 77 \% \quad 45.9$

$830 \% /<10 \% \quad 13.3$

$992 \% /<10 \% \quad 11$

No $\quad 0.8$

No $\quad 1.4$

No 9

No $\quad 7.7$

No $\quad 6.8$

$126 \% /<10 \% \quad$ NA

$252 \% /<10 \% \quad$ NA

$162 \% /<10 \% \quad 2.5$

$140 \% / 49 \%$ NA

No 6

No 1.5

$128 \% /<10 \% \quad$ NA

No $\quad<0.4$

No NA

$804 \% /<10 \% \quad$ NA

NA, not available; $\mathrm{L}_{4}$, levothyroxine; lost to $\mathrm{FU}$, lost to follow-up.

${ }^{a}$ Relapse of GD during pregnancy after more than 2 years of euthyroidism following ATD treatment.

${ }^{b}$ Remission of GD early in pregnancy followed by late relapse requiring a new course of ATD treatment. (rise), Rise of TBII during pregnancy.

${ }^{C} A T D$ continued until the end of pregnancy.

${ }^{\mathrm{d}}$ ATD stopped during pregnancy because of remission of GDm. 


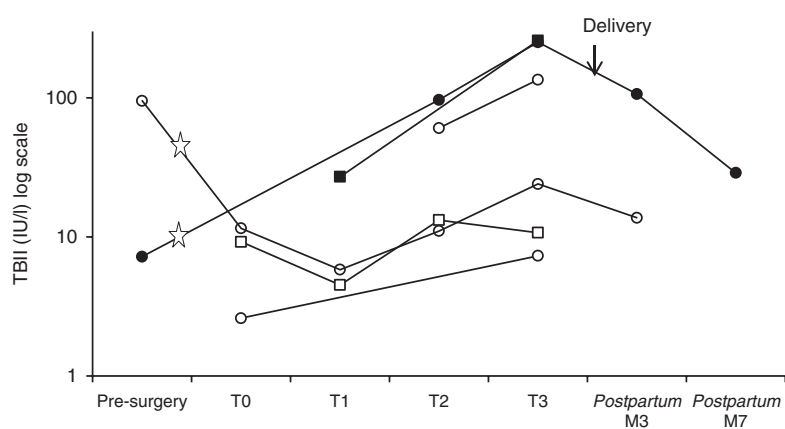

Figure 1

Evolution of TBII in the six mothers who showed a rise in TBII values during pregnancy. Dots, mothers with a past history of GD. Squares, mothers with active GD during pregnancy. Filled markers, mothers of hyperthyroid neonates; empty markers, mothers of euthyroid neonates. Stars, time of surgery.

median age of the women at the beginning of pregnancy was 31 years (range, 22-41).

Twenty mothers of 21 neonates (one twin pregnancy) had a past history of GD. All were euthyroid and had normal TSH levels with $(n=17)$ or without levothyroxine $\left(\mathrm{L}-\mathrm{T}_{4}\right)$ treatment $(n=3)$ during pregnancy. The median time since radical treatment was 19 months (range, 2-132).

Twenty-five mothers of 26 neonates (one twin pregnancy) had active GD, including three recurrences of hyperthyroidism in mothers medically cured 2-3 years before pregnancy. All but one were being treated with ATD; one patient (case no. 6) receiving no treatment was being monitored for subclinical hyperthyroidism. One patient (case no. 5) with GD diagnosed during pregnancy was lost to follow-up and discontinued treatment after 8 weeks of gestation. As given in Table 2, ATD could be stopped, because of remission of hyperthyroidism, in 13 women out of the 21 for whom the information was available, after a median duration of 22 weeks of pregnancy (range, 13-36 weeks). TBII level remained above $1.5 \mathrm{IU} / 1$ in all but two. Patients 3 and 39 relapsed at 31 and 27 weeks of pregnancy respectively.

\section{TBII evolution during pregnancy}

The evolution of TBII during pregnancy was available for 42 pregnancies (Table 1). TBII level decreased or remained stable in 36 pregnancies ( $86 \%$ ) but unexpectedly rose in six (Fig. 1). Two cases had active GD (cases 5 and 39). The four others had a past history of GD: two had been cured after ATD treatment and did not relapse during pregnancy (cases 30 and 36), and two had been operated on 12 months before pregnancy and showed a spontaneous decrease in TBII concentration after delivery (cases 2 and 31).

\section{Neonatal thyroid status}

As shown in Table 2, nine neonates were born with hyperthyroidism, 35 with euthyroidism, and three with hypothyroidism. The cases of the nine hyperthyroid neonates (cases 1-9) are detailed in Table 3. Cases 2 and 5 were issued from mothers whose TBII values increased during pregnancy.

Hyperthyroidism was transient and remitted spontaneously within 3-45 days in four. The five other neonates had to be treated with ATD, two in the intensive care unit. In case 3, hyperthyroidism was delayed to day 5 because of ATD treatment in the mother until delivery. The median duration of ATD treatment was 60 days (range, 14-80), and the TBII value normalized after a median of 3 months (range, 35-120 days). Four neonates had normal thyroid parameters when ATD was discontinued, though one required $\mathrm{L}^{-\mathrm{T}_{4}}$ substitution for an additional 5 months.

Table 3 Clinical and biological evolution of hyperthyroid neonates.

\begin{tabular}{ll}
\hline Case no. & $\begin{array}{l}\text { Clinical manifestations } \\
2\end{array}$ \\
$\begin{array}{ll}\text { Tachycardia } \\
\text { Respiratory distress, tachycardia, hyperactivity, } \\
\text { polycthemia, and hypertension }\end{array}$ \\
3 & None \\
4 & None \\
5 & Respiratory distress, pulmonary hypertension, \\
6 & tachycardia, and goiter \\
7 & None \\
8 & None \\
9 & None
\end{tabular}

Highest $\mathbf{f t}_{\mathbf{4}}(\mathrm{pmol} / \mathrm{l})$
63.2
81.8
59
64
59.2
32
33
34
30

\begin{tabular}{l} 
Treatment \\
\hline PTU \\
PTU $+{\mathrm{L}-T_{4}}$ \\
$\mathrm{CBZ}$ \\
$\mathrm{CBZ}+\mathrm{L}-\mathrm{T}_{4}$ \\
$\mathrm{CBZ}$ \\
None \\
None \\
None \\
None
\end{tabular}

\begin{tabular}{l} 
Time to TBII negative \\
\hline 35 days \\
4 months \\
3 months \\
2.5 months \\
3 months \\
NA \\
NA \\
NA \\
NA
\end{tabular}

NA, not available; $\mathrm{L}_{\mathrm{T}}$, levothyroxine; CBZ, carbimazole; PTU, propylthiouracile. 

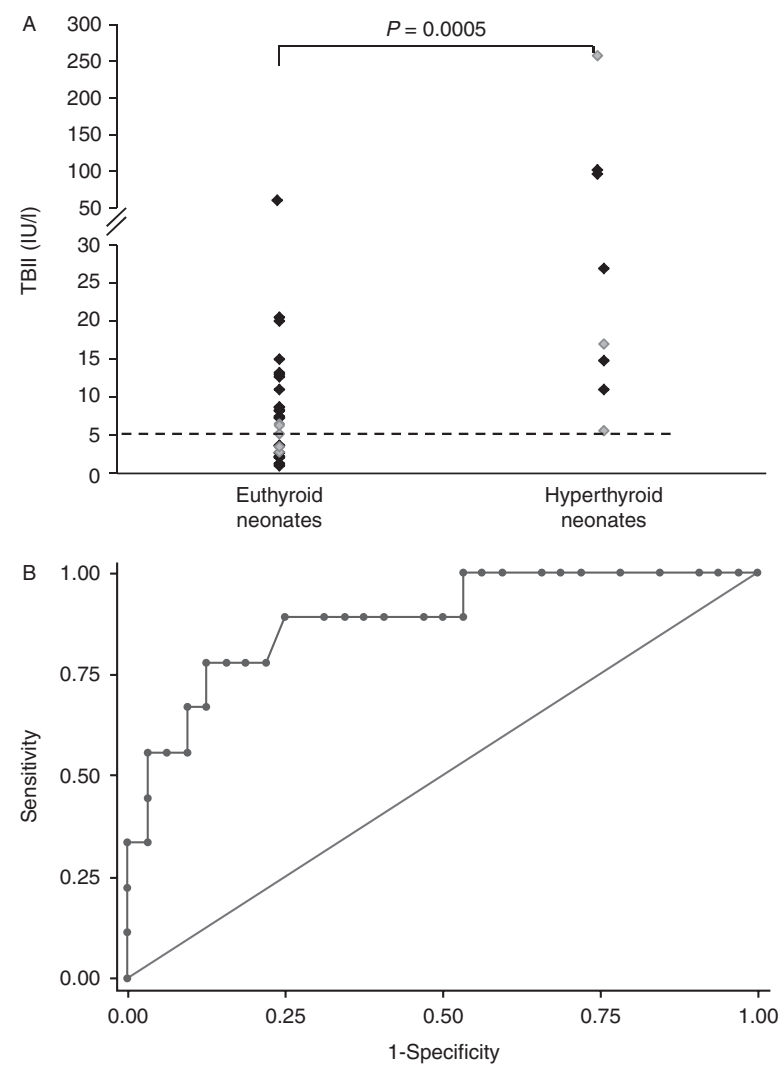

Area under the ROC curve $=0.8837$

\section{Figure 2}

(A) Neonatal thyroid status according to maternal TBII values at T2 (black dots) or if not available at T3 (gray dots). No hyperthyroid neonate was born to a mother with TBII below $5.6 \mathrm{IU} / \mathrm{I}$. (B) ROC curve: area under the curve ROC area is 0.89 $(95 \% \mathrm{Cl}(0.71-0.96))$. For a cutoff value of $5 \mathrm{IU} / \mathrm{l}$, the sensitivity is $100 \%$ and specificity is $43 \%$. Hypothyroid neonates were excluded from this analysis. The 41 neonates born to mothers that had a T2 and/or a T3 TBII determination were included.

Three neonates were born with biochemically confirmed hypothyroidism (cases 45-47), spontaneously regressive within 3-45 days. In cases 45 and 47, hypothyroidism was due to an excessive ATD treatment in the mothers. Neonatal TSH values were 42 and $11 \mathrm{mIU} / \mathrm{l}$ respectively. Neonate no. 46 was born to a mother on substitutive $\mathrm{L}_{-} \mathrm{T}_{4}$ after radioactive iodine (RAI); he was clinically euthyroid but had a TSH value of $19 \mathrm{mIU} / \mathrm{l}$ at birth.

\section{Predictive factors of fetal outcome}

Neonatal thyroid status according to TBII and TSAb maternal values • Only 20 out of 45 mothers had a bioassay determination. However, the two groups of patients who did or did not have a bioassay determination did not differ on age $(P=0.133)$, history of GD (active or cured before pregnancy, $P=0.502$ ), or neonatal thyroid status (euthyroidism or hyperthyroidism $P=0.957$, hypothyroid neonates being excluded of this analysis). However, they differed on mean TBII value $(P=0.045)$ with higher values in the group that had a bioassay (mean, $33 \mathrm{IU} / 1 \pm 60$ ), than in the other group (mean, $11 \mathrm{IU} / 1 \pm 20$ ). As shown in Fig. 2, none of the neonates born to mothers harboring TBII values below $5.6 \mathrm{IU} / 1$ during the second half of pregnancy were hyperthyroid. From the ROC curve (area $0.89,95 \%$ CI (0.71-0.96)), a TBII value over 5 IU/l at $\mathrm{T} 2$ or $\mathrm{T} 3$ predicted the neonatal hyperthyroidism with a sensitivity of $100 \%$ with $95 \%$ CI (69-100\%). However, specificity was only $43 \%$ with $95 \%$ CI (26-62\%).

No case of neonatal hyperthyroidism was observed when maternal TSAb was below $400 \%(n=13)$, regardless of the TBII value (Fig. 3). By contrast, the four mothers of hyperthyroid neonates who had a TSAb determination had high TSAb values, ranging from 412 to $1584 \%$.

As depicted in the ROC curve on Fig. 3 (ROC area 0.93, 95\% CI (0.67-0.98)), a TSAb value above $400 \%$ increased the specificity of prediction of neonatal hyperthyroidism to $85 \%$ (95\% CI (57-98\%)), with 100\% sensitivity (95\% CI (39-100\%)).

Maternal treatment during pregnancy $>$ Excluding the patient lost to follow-up, none of the mothers of hyperthyroid neonates, who required ATD treatment during pregnancy, could stop their treatment before delivery. All the mothers in long-term remission after medical treatment and who remained in remission during pregnancy gave birth to euthyroid neonates.

Neonatal TBII value $\bullet$ Data are shown in Fig. 4. TBII assay was carried out in 24 neonates, including seven of the nine hyperthyroid neonates, between 1 and 3 days post delivery. None of the hyperthyroid neonates had a TBII value below $6.5 \mathrm{IU} / \mathrm{l}$. Using the cutoff value of $6 \mathrm{IU} / \mathrm{l}$, we could predict neonatal hyperthyroidism with $100 \%$ sensitivity and $53 \%$ specificity. Neonatal TBII values correlated with maternal TBII values at T3 $\left(R^{2}=0.80\right)$.

\section{Discussion}

The coincidence of GD and pregnancy is a challenging situation that exposes the fetus to a rare but potentially serious risk of thyroid dysfunction: either hyperthyroidism caused by the stimulating effect of TRAb or hypothyroidism due to maternal ATD treatment. 

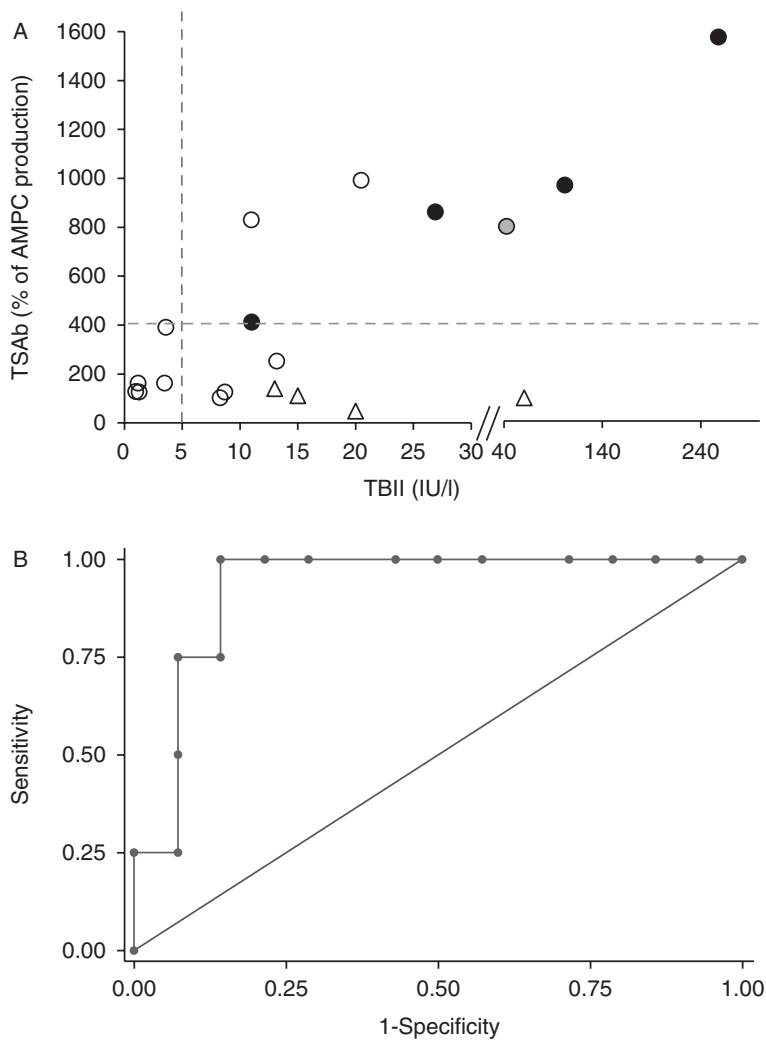

Area under the ROC curve $=0.9286$

\section{Figure 3}

(A) Neonatal thyroid status according to maternal TSAb and T2 TBII. Mothers of euthyroid neonates are represented as empty dots, those of hyperthyroid neonates as filled dots, and those of euthyroid neonates having significant associated blocking activity (TBAb) as empty triangles. Gray dot represents the mother of an iatrogenic hypothyroid neonate (case 47).

The mother, who gave birth to a hyperthyroid neonate and in whom TBII was 5.6 IU/I, did not have TSAb measured. (B) Cutoff values at $5 \mathrm{IU} / \mathrm{l}$ for TBII and $400 \%$ for TSAb predicted

hyperthyroid neonates with only two false positives. ROC curve: area under the curve ROC area is 0.93 (95\% Cl (0.67-0.98)). For a cutoff value of $400 \%$, the sensitivity is $100 \%$ and the specificity is $85.7 \%$ (18 mothers who had a TSAb activity value and a TBII value during T2 and/or T3 were included whereas the mother of the hypothyroid neonate was excluded).

The definitive assessment of fetal thyroid status requires cordocentesis, a hazardous procedure which can lead to fetal death. Therefore, surrogate markers are required to enable a noninvasive evaluation of fetal thyroid status: fetal signs suggestive of thyroid dysfunction as well as fetal thyroid size, but also maternal condition, including TRAb value and ATD dosage.
The TBII value predictive of neonatal hyperthyroidism has been clearly established with the first generation TBII assay. Previous studies reported an increased risk if TBII level was over $40 \mathrm{IU} / 1$ (normal range, <10 IU/1) (25), or over 40 or $70 \%(26,27)$ (normal, $<10-15 \%$ ) in late T3. Today, the TBII first-generation assay has been widely replaced by the second-generation assay, and yet only one short study has investigated the TBII value predictive of neonatal hyperthyroidism using this assay (19). The authors compared TBII values determined by four assays, and tried to establish equivalence between first- and second-generation assays. Our study included only two hyperthyroid neonates, and any conclusions about the TBII value predictive of neonatal thyroid dysfunction were thus hard to draw. This study, although retrospective, included a large number of TRAb-positive patients and 12 cases of fetal or neonatal thyroid dysfunction, and thus provides powerful new information. It allowed us to establish the TBII threshold predictive of neonatal hyperthyroidism and to highlight the utility of the TSAb bioassay. Among the 12 neonates with thyroid dysfunction, nine were hyperthyroid and three hypothyroid.

All hyperthyroid neonates were born to mothers harboring TBII values above $5 \mathrm{IU} / 1$ at T2, i.e. 3.3 times the detection level. This threshold value was provided by a mother who relapsed with GD late in pregnancy, and for whom no TBII determination had been made before T3. TBII values generally decrease during pregnancy $(10,28)$, as was observed for most of our patients. Therefore, it could be argued that our threshold value, derived from a TBII determination at T3, is underestimated. Yet, in this case of late relapse, this value is clinically relevant and provided high sensitivity but low specificity in predicting risk.
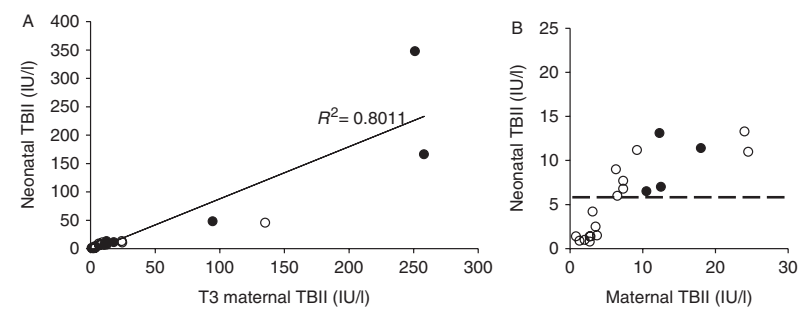

\section{Figure 4}

(A) The values for TBII measured for the mother at T3 and the neonate in the first week are correlated. Filled dots, hyperthyroid neonates; empty dots, euthyroid neonates.

(B) Focus on lowest maternal and fetal TBII values:

all hyperthyroid neonates had TBII values above 6.5. 
Our TBII cutoff value is twofold lower than expected from Kamijo's (19) study using a second-generation assay. However, it does agree with current guidelines $(12,13,29)$ that recommend a TRAb determination at T2, between 20 and 24 WG, and a close follow-up if TRAb is over two to three times the upper limit. This threshold was extrapolated from previous studies using first-generation TBII assay and bioassay. Our study, through clinical data, confirms that it is clinically relevant.

The prediction was improved when the result of an additional bioassay was taken into account. Indeed, among neonates born to mothers harboring TBII $>5$ IU/l, none was born hyperthyroid when TSAb value was below $400 \%$. The mothers of hyperthyroid neonates in whom a bioassay has been performed in this series had significantly higher TBII values. Therefore, the threshold value of TSAb needs to be confirmed in a larger study with a bioassay performed in every mother with detectable TBII level during pregnancy. However, our data are concordant with the literature: levels of TSAb reported to be predictive of neonatal hyperthyroidism were a stimulation of cAMP over $350-500 \%$ in T3 $(10,25,27,30)$ or over $500 \%$ in T2 (31).

This combined criteria, i.e. TBII level $>5 \mathrm{IU} / 1$ and TSAb $>400 \%$, could enable the identification of at risk pregnancies with an improved specificity. Tamaki et al. (32) also reported, with a first-generation TBII assay, that the best predictive factor for neonatal hyperthyroidism was the association of high values for both TBII and TSAb. Bioassay is not, however, widely available and is time consuming and expensive. Therefore, we suggest an integrative strategy achievable in daily practice: first screening at-risk patients with TBII, followed by bioassay when TBII value is above 5 IU/l. At risk pregnancies should then be carefully monitored, with repeated fetal thyroid ultrasound, which is the best tool to identify fetal dysthyroidism, as demonstrated by Luton et al. (33). This strategy and the threshold value of TSAb have to be confirmed in a larger study, considering the fact that a bioassay had not been performed in all women of this series.

In accordance with Mortimer et al. (34), we found a high correlation between maternal and neonatal TBII values, illustrating the increased placental permeability to TRAb in T3 when fetal levels reach maternal ones $(35,36)$. As in the recent report of Besançon et al. (37), we found an increased risk of neonatal hyperthyroidism when neonatal TBII levels were elevated at birth, with a cutoff value of 6 IU/l, higher than that found by Skuza et al. (38) on a smaller series of 14 neonates with first-generation TBII determination. Despite its high sensitivity, the clinical usefulness of this threshold may be questionable as results are often delayed.
In this series, ATD requirement until the end of pregnancy was indicative of a risk of hyperthyroidism in the neonate, as no mother of a hyperthyroid child, with an active GD during pregnancy, could stop ATD treatment before delivery.

Previous guidelines indicated no risk of thyroid dysfunction in the neonates born to mothers medically cured before pregnancy (2). However, in our series of pregnant women with positive TBII value, recurrences of hyperthyroidism occurred in three cases after long-lasting previous remission, one of whom gave birth to a hyperthyroid neonate. In our view, even women in remission after medical treatment should be informed of the low but genuine risk of relapse during pregnancy.

Medical treatment for GD led to spontaneous hypothyroidism in three mothers in our series, in whom TBII-positive values were maintained, suggestive of TRAbblocking activity. This could have exposed their fetus to a risk of passive autoimmune hypothyroidism (4). The coexistence of stimulating and blocking activities may explain the resulting euthyroidism in the neonates.

We observed an unexpected rise in TBII in six patients, four of whom were in long-term remission for GD after medical or surgical treatment and displayed no clinical or biological relapse during pregnancy. Two of these six women gave birth to a hyperthyroid neonate. A few similar cases of TBII rise during pregnancy, not followed by GD relapse, have been reported previously $(39,40)$, suggesting the need for monitoring TRAb during pregnancy as far as preconceptional TRAb are detectable.

Two neonates had transient iatrogenic hypothyroidism, which could have been avoided using minimal doses of ATD, in order to maintain the maternal level of $\mathrm{fT}_{4}$ at the upper limit of the nonpregnant reference range, as recent guidelines recommend $(12,13)$. The third case of hypothyroidism, occurring in a mother cured for GD before pregnancy, could be caused by increasing blocking activity during T3, as reported previously (41).

In conclusion, according to the results of our study, a maternal second-generation TBII assay value over 5 IU/1 during T2 indicates a risk for fetal and neonatal hyperthyroidism. Coexistence of TBII level above 5 IU/l and significantly high TSAb activity could specify this risk and require close monitoring, including repeated thyroid fetal ultrasound. Larger studies should evaluate the efficiency of such a strategy. As unexpected and considerable rises in TBII values were observed during pregnancy in a few women with active or past GD, we suggest to perform systematically a control during $\mathrm{T} 2$ in all mothers with detectable TBII before pregnancy. 


\section{Declaration of interest}

The authors declare that there is no conflict of interest that could be perceived as prejudicing the impartiality of the research reported.

\section{Funding}

This research did not receive any specific grant from any funding agency in the public, commercial or not-for-profit sector.

\section{Acknowledgements}

The authors thank Drs Nadine Bossard, Sybil Charrière, David Cheillant, Gérard Sautot, Cécile Dubest, Pierre-Yves Echallier, Jacques Bernard, Chantal Bully, Catherine Thomas-Martin, Alexandra Crand, Gérald Raverot, Elizabeth Drevard, Sylvie Villar-Fimbel, Agnès Perrin, Aude Brac de la Perrière, Pierre Sérusclat, Aurélie Decaudain, Audrey Dubet, Corinne Sagot, Claire Damatte-Fauchery, Myriam Moret, Aurélie Brosse, Myriam Oliel, Christine Martin, Stéphanie Chabroux, Marc Nicolino, Armelle Noguer, Claire Lise Gay, Annie André-Tiercelin, Ling Brigant, Thierry Finck, Salah Milane, Olivier Tariel, Jacqueline Ginon, Catherine Battie, and Olivier Dupuis for their active collaboration. The authors thank Emily Witty from Angloscribe for helping with the English editing.

\section{References}

1 Cooper DS \& Laurberg P. Hyperthyroidism in pregnancy. Lancet. Diabetes \& Endocrinology 20131 238-249. (doi:10.1016/S22138587(13)70086-X)

2 Laurberg P, Bournaud C, Karmisholt J \& Orgiazzi J. Management of Graves' hyperthyroidism in pregnancy: focus on both maternal and foetal thyroid function, and caution against surgical thyroidectomy in pregnancy. European Journal of Endocrinology 2009160 1-8. (doi:10.1530/EJE-08-0663)

3 Polak M. Hyperthyroidism in early infancy: pathogenesis, clinical features and diagnosis with a focus on neonatal hyperthyroidism. Thyroid 19988 1171-1177. (doi:10.1089/thy.1998.8.1171)

4 McKenzie JM \& Zakarija M. Fetal and neonatal hyperthyroidism and hypothyroidism due to maternal TSH receptor antibodies. Thyroid 1992 2 155-159. (doi:10.1089/thy.1992.2.155)

5 Zimmerman D. Fetal and neonatal hyperthyroidism. Thyroid 19999 727-733. (doi:10.1089/thy.1999.9.727)

6 Burrow GN, Fisher DA \& Larsen PR. Maternal and fetal thyroid function. New England Journal of Medicine 1994331 1072-1078. (doi:10.1056/NEJM199410203311608)

7 Fisher DA \& Klein AH. Thyroid development and disorders of thyroid function in the newborn. New England Journal of Medicine $1981 \mathbf{3 0 4}$ 702-712. (doi:10.1056/NEJM198103193041205)

8 Weetman AP. Graves' disease. New England Journal of Medicine 2000343 1236-1248. (doi:10.1056/NEJM200010263431707)

9 Szinnai G, Lacroix L, Carré A, Guimiot F, Talbot M, Martinovic J, Delezoide AL, Vekemans M, Michiels S, Caillou B et al. Sodium/iodide symporter (NIS) gene expression is the limiting step for the onset of thyroid function in the human fetus. Journal of Clinical Endocrinology and Metabolism 200792 70-76. (doi:10.1210/jc.2006-1450)

10 Zakarija M \& McKenzie JM. Pregnancy-associated changes in the thyroid-stimulating antibody of Graves' disease and the relationship to neonatal hyperthyroidism. Journal of Clinical Endocrinology and Metabolism 198357 1036-1040. (doi:10.1210/jcem-57-5-1036)

11 Hoffman WH, Sahasrananan P, Ferandos SS, Burek CL \& Rose NR. Transient thyrotoxicosis in an infant delivered to a long-acting thyroid stimulator (LATS)- and LATS protector-negative, thyroid-stimulating antibody-positive woman with Hashimoto's thyroiditis. Journal of Clinical Endocrinology and Metabolism 198254 354-356. (doi:10.1210/jcem-54-2-354)

12 De Groot L, Abalovich M, Alexander EK, Amino N, Barbour L, Cobin RH, Eastman CJ, Lazarus JH, Luton D, Mandel SJ et al. Management of thyroid dysfunction during pregnancy and postpartum: an Endocrine Society clinical practice guideline. Journal of Clinical Endocrinology and Metabolism 201297 2543-2565. (doi:10.1210/jc.2011-2803)

13 Stagnaro-Green A, Abalovich M, Alexander E, Azizi F, Mestman J, Negro R, Nixon A, Pearce EN, Soldin OP, Sullivan S et al. Guidelines of the American Thyroid Association for the diagnosis and management of thyroid disease during pregnancy and postpartum. Thyroid 201121 1081-1125. (doi:10.1089/thy.2011.0087)

14 Southgate K, Creagh F, Teece M, Kingswood C \& Rees Smith B. A receptor assay for the measurement of TSH receptor antibodies in unextracted serum. Clinical Endocrinology 198420 539-548. (doi:10.1111/j.1365-2265.1984.tb00102.x)

15 Smith BR \& Hall R. Thyroid-stimulating immunoglobulins in Graves' disease. Lancet 19742 427-431. (doi:10.1016/S0140-6736(74)91815-7)

16 Costagliola S, Morgenthaler NG, Hoermann R, Badenhoop K, Struck J, Freitag D, Poertl S, Weglöhner W, Hollidt JM, Quadbeck B et al. Second generation assay for thyrotropin receptor antibodies has superior diagnostic sensitivity for Graves' disease. Journal of Clinical Endocrinology and Metabolism 199984 90-97.

17 Massart C, Orgiazzi J \& Maugendre D. Clinical validity of a new commercial method for detection of TSH-receptor binding antibodies in sera from patients with Graves' disease treated with antithyroid drugs. Clinica Chimica Acta 2001304 39-47. (doi:10.1016/S00098981(00)00385-5)

18 Filetti S, Foti D, Costante G \& Rapoport B. Recombinant human thyrotropin (TSH) receptor in a radioreceptor assay for the measurement of TSH receptor autoantibodies. Journal of Clinical Endocrinology and Metabolism 199172 1096-1101. (doi:10.1210/jcem-72-5-1096)

19 Kamijo K. TSH-receptor antibodies determined by the first, second and third generation assays and thyroid-stimulating antibody in pregnant patients with Graves' disease. Endocrine Journal 200754 619-624. (doi:10.1507/endocrj.K06-196)

20 Raverot V, Bournaud C, Sassolas G, Orgiazzi JJ, Claustrat F, Gaucherand P, Mellier G, Claustrat B, Borson-Chazot F \& Zimmermann M. French pregnant women in the Lyon area are iodine deficient and have elevated serum thyroglobulin concentrations. Thyroid 201222 522-528. (doi:10.1089/thy.2011-0184)

21 Kapelari K, Kirchlechner C, Högler W, Schweitzer K, Virgolini I \& Moncayo R. Pediatric reference intervals for thyroid hormone levels from birth to adulthood: a retrospective study. BMC Endocrine Disorders 20088 15. (doi:10.1186/1472-6823-8-15)

22 Kratzsch J \& Pulzer F. Thyroid gland development and defects. Best Practice \& Research. Clinical Endocrinology \& Metabolism 200822 57-75. (doi:10.1016/j.beem.2007.08.006)

23 Madec AM, Clavel S, Stefanutti A \& Orgiazzi J. Blocking antithyrotropin receptor antibodies desensitize cultured human thyroid cells. Endocrinology 1988123 2062-2066. (doi:10.1210/endo-123-4-2062)

24 Kasagi K, Konishi J, Iida Y, Ikekubo K, Mori T, Kuma K \& Torizuka K. A new in vitro assay for human thyroid stimulator using cultured thyroid cells: effect of sodium chloride on adenosine $3^{\prime}, 5^{\prime}$-monophosphate increase. Journal of Clinical Endocrinology and Metabolism $1982 \mathbf{5 4}$ 108-114. (doi:10.1210/jcem-54-1-108)

25 Clavel S, Madec AM, Bornet H, Deviller P, Stefanutti A \& Orgiazzi J. Anti TSH-receptor antibodies in pregnant patients with autoimmune thyroid disorder. British Journal of Obstetrics and Gynaecology 199097 1003-1008. (doi:10.1111/j.1471-0528.1990.tb02472.x)

26 Mitsuda N, Tamaki H, Amino N, Hosono T, Miyai K \& Tanizawa O. Risk factors for developmental disorders in infants born to women with Graves disease. Obstetrics and Gynecology 199280 359-364. 
27 Matsuura N, Konishi J, Fujieda K, Kasagi K, Iida Y, Hagisawa M, Fujimoto S, Fukushi M \& Takasugi N. TSH-receptor antibodies in mothers with Graves' disease and outcome in their offspring. Lancet 19881 14-17. (doi:10.1016/S0140-6736(88)91001-X)

28 Amino N, Izumi Y, Hidaka Y, Takeoka K, Nakata Y, Tatsumi KI, Nagata A $\&$ Takano T. No increase of blocking type anti-thyrotropin receptor antibodies during pregnancy in patients with Graves' disease. Journal of Clinical Endocrinology and Metabolism 200388 5871-5874. (doi:10.1210/ jc.2003-030971)

29 Bahn Chair RS, Burch HB, Cooper DS, Garber JR, Greenlee MC, Klein I, Laurberg P, McDougall IR, Montori VM, Rivkees SA et al. Hyperthyroidism and other causes of thyrotoxicosis: management guidelines of the American Thyroid Association and American Association of Clinical Endocrinologists. Endocrine Practice 201117 456-520. (doi:10.4158/EP.17.3.456)

30 Wallace C, Couch R \& Ginsberg J. Fetal thyrotoxicosis: a case report and recommendations for prediction, diagnosis, and treatment. Thyroid 19955 125-128. (doi:10.1089/thy.1995.5.125)

31 Peleg D, Cada S, Peleg A \& Ben-Ami M. The relationship between maternal serum thyroid-stimulating immunoglobulin and fetal and neonatal thyrotoxicosis. Obstetrics and Gynecology 200299 1040-1043. (doi:10.1016/S0029-7844(02)01961-0)

32 Tamaki H, Amino N, Aozasa M, Mori M, Iwatani Y, Tachi J, Nose O, Tanizawa $\mathrm{O} \&$ Miyai K. Universal predictive criteria for neonatal overt thyrotoxicosis requiring treatment. American Journal of Perinatology 19885 152-158. (doi:10.1055/s-2007-999676)

33 Luton D, Le Gac I, Vuillard E, Castanet M, Guibourdenche J, Noel M, Toubert ME, Léger J, Boissinot C, Schlageter MH et al. Management of Graves' disease during pregnancy: the key role of fetal thyroid gland monitoring. Journal of Clinical Endocrinology and Metabolism 200590 6093-6098. (doi:10.1210/jc.2004-2555)

34 Mortimer RH, Tyack SA, Galligan JP, Perry-Keene DA \& Tan YM. Graves' disease in pregnancy: TSH receptor binding inhibiting immunoglobulins and maternal and neonatal thyroid function. Clinical Endocrinology 199032 141-152. (doi:10.1111/j.1365-2265.1990.tb00850.x)

35 Gitlin D. Development and metabolism of the immune globulins. In Immunologic Incompetence. Eds BM Kagan \& Stiehm. Chicago: Year Book Medical Publishers, Inc., 1971.

36 Chan GW \& Mandel SJ. Therapy insight: management of Graves' disease during pregnancy. Nature Clinical Practice. Endocrinology \& Metabolism 20073 470-478. (doi:10.1038/ncpendmet0508)

37 Besançon A, Beltrand J, Le Gac I, Luton D \& Polak M. Management of neonates born to women with Graves' disease: a cohort study. European Journal of Endocrinology 2014170 855-862. (doi:10.1530/EJE-13-0994)

38 Skuza KA, Sills IN, Stene M \& Rapaport R. Prediction of neonatal hyperthyroidism in infants born to mothers with Graves disease. Journal of Pediatrics 1996128 264-268. (doi:10.1016/S0022-3476(96)70405-5)

39 Hamada N, Momotani N, Ishikawa N, Yoshimura Noh J, Okamoto Y, Konishi T, Ito $\mathrm{K} \&$ Ito $\mathrm{K}$. Persistent high TRAb values during pregnancy predict increased risk of neonatal hyperthyroidism following radioiodine therapy for refractory hyperthyroidism. Endocrine Journal 2011 58 55-58. (doi:10.1507/endocri.K10E-123)

40 Tamaki H, Amino N, Iwatani Y, Tachi J, Mitsuda N, Tanizawa O \& Miyai K. Discordant changes in serum anti-TSH receptor antibody and antithyroid microsomal antibody during pregnancy in autoimmune thyroid diseases. Thyroidology 19891 73-77.

41 Kung AW \& Jones BM. A change from stimulatory to blocking antibody activity in Graves' disease during pregnancy. Journal of Clinical Endocrinology and Metabolism 199883 514-518.

Received 28 March 2014

Revised version received 26 June 2014

Accepted 3 July 2014 